\title{
Australian graduating nurses' knowledge, intentions and beliefs on infection prevention and control: a cross-sectional study
}

\author{
Brett G Mitchell ${ }^{1} 2^{*}$, Richard Say ${ }^{3}$, Anne Wells ${ }^{4}$, Fiona Wilson ${ }^{4}$, Linda Cloete ${ }^{1}$ and Lucinda Matheson ${ }^{1}$
}

\begin{abstract}
Background: In recent year, national bodies have been actively addressing the increasing concern on the spread of healthcare-associated infections (HAls). The current study measures the knowledge, intentions and beliefs of third-year Australian nursing students on key infection prevention and control (IPC) concepts.

Methods: A cross-sectional study of final-year undergraduate nursing students from Schools of Nursing at six Australian universities was undertaken. Students were asked to participate in an anonymous survey. The survey explored knowledge of standard precautions and transmission based precautions. In addition intentions and beliefs towards IPC were explored.

Results: 349 students from six universities completed the study. 59.8\% (95\% Cl 58.8-60.8\%) of questions were answered correctly. Significantly more standard precaution questions were correctly answered than transmission-based precaution questions $(p<0.001)$. No association was found between self-reported compliance with IPC activities and gender or age. Certain infection control issues were correlated with the percentage of correctly answered transmission-based precaution questions. The participants were most likely to seek infection control information from an infection control professional.

Conclusion: Knowledge on transmission-based precautions was substandard. As transmission-based precautions are the foundation of IPC for serious organisms and infections, education institutions should reflect on the content and style of educational delivery on this topic.
\end{abstract}

\section{Background}

In recent years, there has been an effort by organisations internationally to reduce the spread of healthcareassociated infections (HAIs). Healthcare associated infection is the contemporary term used to refer to infections acquired in healthcare facilities and infections that occur as a result of healthcare interventions [1]. The effect of HAIs are not only felt by individual patients through increased morbidity and mortality, but also by a health service through higher costs associated with infections. The magnitude of the effect of HAIs on patients is evidenced by a report from the World Health Organisation, which

\footnotetext{
* Correspondence: brett.mitchell@avondale.edu.au

'Faculty of Nursing and Health, Avondale College of Higher Education,

Wahroonga, NSW 2076, Australia

${ }^{2}$ School of Nursing, Midwifery and Paramedicine, Australian Catholic

University, Dickson, ACT, Australia

Full list of author information is available at the end of the article
}

suggests that $7.6 \%$ of hospitalised patients will acquire a HAI [2]. This is support by other point prevalence studies who have found similar incidence of infections [3-5]. In response to the prevention of HAIs in Australia, the Australian Commission on Safety and Quality in Health Care (ACSQHC) launched the Healthcare Acquired Infection Prevention Program in 2009 [6], and the National Health and Medical Research Council (NHMRC) released the Australian Guidelines for the Prevention and Control of Infection in Healthcare in 2010 [1].

The ACSQHC developed initiatives which aim to standardise infection prevention and control (IPC) practice across Australia as a part of a wide strategy to reduce the incidence of HAIs. However, in the approach to reducing HAIs in Australia, there has been little mention of the role of undergraduate education. This is despite evidence pointing towards the pivotal role of the 
undergraduate environment in shaping attitude and building the knowledge of healthcare professionals [7].

The prevention of infection requires a multifaceted approach. Infectious agents can be transmitted from their sources to a susceptible host by a variety of methods, which include direct spread on the hands of healthcare workers, carriage on equipment, and through airflow. The prevention of transmission via these methods can be routinely prevented in healthcare settings using 'standard precautions'. Standard precautions include hand hygiene and the use of personal protection equipment when anticipating contact with blood or bodily fluids. Contact precautions are applied to the care of all patients at all times $[1,8]$. Other modes of transmission for infectious agents are via direct or indirect contact, mucous membrane contact with respiratory secretions (droplet transmission) or inhalation of infectious agents suspected in the air (airborne transmission). These three processes fall under the umbrella term 'transmission based precautions' $[1,8]$.

Despite the well documented use of standard and transmission based precautions to prevent infection, there is a lack of conceptual and theoretical frameworks in the field of IPC [9]. None the less, the first step in informing IPC education in undergraduate curricula is to determine a baseline, described as surveillance in a theoretical framework proposed by Mitchell and Gardner [10]. The current study measures the knowledge, intentions and beliefs of third-year Australian nursing students on key infection prevention and control (IPC).

Clinician education is a key strategy in the reduction of HAIs through IPC programs. The ACSQHC names education as a central tenet in effective IPC strategies $[6,11]$. Overseas, the United States (US) Department of Health and Human Services highlights the critical role of education in IPC, and numerous National Health Service trusts and government departments in the United Kingdom (UK) emphasise the importance of education in IPC $[12,13]$. Despite local and international acknowledgement that education is key, however, concerns surrounding deficits in IPC knowledge amongst clinicians, including attitude towards IPC, continue to be reported [14-16]. Knowledge is a precursor to changing entrenched attitude, and numerous studies have emphasised the importance of both of these components for a sustainable behavioural change amongst clinicians [17]. This relationship among knowledge, attitude and behavioural change has been specifically researched in relation to IPC $[14,18]$.

Pre-registration training plays a crucial role in improved clinician compliance to IPC [7], and the NHMRC asserts that undergraduate clinician programs serve as a key environment where knowledge acquisition on IPC should occur [1]. A number of studies highlight the inadequacy of many undergraduate programs to effectively train students of various clinical disciplines [7,13,19-22].
This finding implies the possible causal link between undergraduate education and the lack of clinician compliance to IPC policy.

A number of authors have pointed out the lack of research which examines the effectiveness of IPC programmes in undergraduate nursing curricula $[13,19,23]$. This case is particularly notable in Australia. Nurses represent the largest healthcare service labour group which has a high frequency of contact with patients [24], so IPC education of nurses in undergraduate programmes warrants attention. To the best of our knowledge, no study which examines undergraduate nursing IPC programmes in Australia has been undertaken.

The data collected in this study measured IPC knowledge, intentions and beliefs of final-year nursing students across six universities in Australia. We believe that this research can act as a starting point to inform undergraduate curricula in Australia on effective IPC training.

\section{Methods}

\section{Aim}

This study aims to determine graduating nursing students' knowledge of and intentions towards IPC practices. The following research questions which underpin this project are directed to graduating nursing students:

1. What is their knowledge of standard precautions and its application?

2. What is their knowledge of transmission-based precautions and its application?

3. How and where do they seek information about IPC activities?

4. What is their belief of infection risk for IPC activities?

\section{Design}

A cross-sectional study was used in this research.

\section{Setting and participants}

The participants in this study were final-year nursing bachelorette degree students at six universities in Australia. The students were surveyed at the end of their final year of study, with their graduation anticipated to occur in the following three months.

\section{Data collection}

The department heads of the nursing and midwifery schools of eight universities were contacted, and access to their final-year nursing students was requested. Six schools agreed to participate and forwarded an invitation e-mail to their students. In the invitation, the students were asked to participate in an anonymous survey, with no obligation to participate. To improve the response rate, we offered an incentive of winning an Ipad to prospective respondents. 
An online survey was developed with the help of the research team, trialled with infection control experts and cross-referenced against national guidelines to determine the correct response [1]. The survey asked basic demographic information, including age, sex, education institution and anticipated data of graduation. A measure of academic performance, such as a grade point average was not collected - the pilot of the survey indicated a lack of awareness of this and inconsistency in application.

The questions contained in the survey consisted of ten multiple choice, seven true/false and questions that required the student to rank responses. The survey topics explored the respondents' knowledge and application of standard and transmission-based precautions, as well as built on previous studies and existing tools $[16,25,26]$ (Additional file 1). Questions relating to hand hygiene were taken from an online competency packaged developed by Hand Hygiene Australia [27]. This package has been extensively used by nurses in the Australian hospital system. The survey was piloted on second yearnursing students and subsequently revised on the basis of feedback from the pilot.

\section{Ethical considerations}

The study was approved by the Avondale College for Higher Education Human Research Ethics Committee (2013:22). All participants provided consent to participate.

\section{Statistical analysis}

Data were analysed with IBM Statistic SPSS (SPSS, Chicago, IL, USA) [28]. The responses to questions used in the survey were categorised into two groups: questions which can be marked in a dichotomous manner (i.e., correct or incorrect) and questions which explored intentions and beliefs. An overall percentage score was calculated for correctly answered questions. In addition, the questions were further divided into two themes: standard precaution questions and transmission-based precaution questions (Figure 1).

For proportions, 95\% confidence intervals (CI) were calculated for Poisson distributed counts. Independent t-tests were performed to compare two variables mean scores. Comparisons of non-parametric independent demographic data were conducted with the use of the Mann-Whitney test. For questions which required the participants to rank a response, mean scores and standard deviations were calculated. Analysis of variance (ANOVA) was used to compare any differences between variable mean scores. Correlations between variables were calculated with Spearman's correlation coefficient or Kendall's tau for non-parametric correlations.

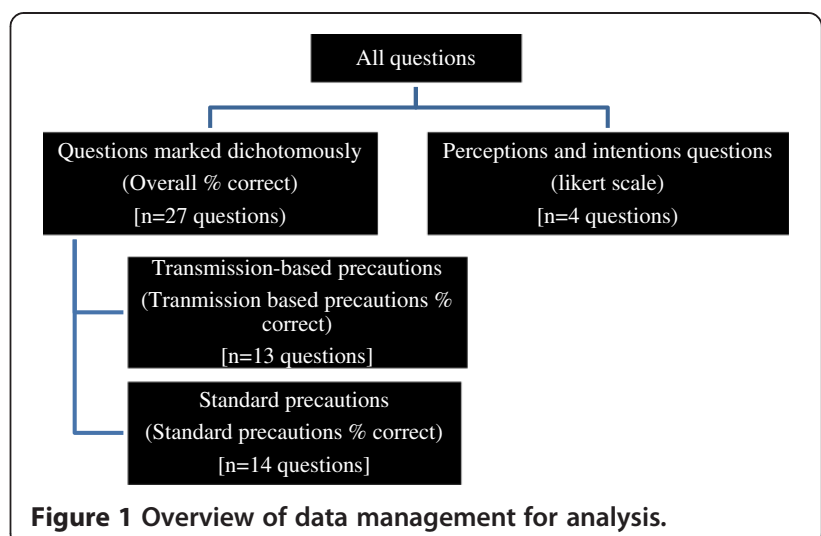

\section{Results}

Overview

A total of 349 students from six universities completed the study. The response rate represents $21 \%$ of all graduating student nurses from these institutions. The age of the participants ranged from 19 to 65 years, with a median of 25 years. Of the total respondents, 319 (91.4\%) were female. The percentage of questions correctly answered was 59.8\% (95\% CI 58.8-60.8\%). Table 1 summarises the mean weighted score by demographic. Notably, significantly more standard precaution questions were correctly answered than transmission-based precaution questions $(p<0.001)$. The mean score for the standard and transmission-based precaution questions did not vary between age groups or sex. Table 1 provides a summary of the correct answers by demographic.

Table 1 Percentage of questions answered correctly

\begin{tabular}{|c|c|c|c|c|}
\hline Demographic & $\begin{array}{l}\text { Percentage answered } \\
\text { correctly (mean) }\end{array}$ & $95 \% \mathrm{Cl}$ & SD & $p$ value \\
\hline \multicolumn{5}{|l|}{ Age group (IQR) } \\
\hline $19-21$ years $(n=83)$ & $60.0 \%$ & $57.9-62.1$ & 9.8 & \\
\hline $22-25$ years $(n=87)$ & $60.1 \%$ & $58.3-62.0$ & 8.6 & \\
\hline $26-35$ years $(n=81)$ & $60.3 \%$ & $58.2-62.5$ & 9.7 & \\
\hline$>35$ years $(n=98)$ & $58.9 \%$ & $57.1-60.7$ & 9.4 & 0.74 \\
\hline \multicolumn{5}{|l|}{ Sex } \\
\hline Male $(n=30)$ & $59.7 \%$ & $58.7-60.8$ & 9.4 & 0.68 \\
\hline Female $(n=319)$ & $60.4 \%$ & $57.1-63.6$ & 8.8 & \\
\hline \multicolumn{5}{|l|}{ Question theme } \\
\hline $\begin{array}{l}\text { Standard precautions } \\
(\mathrm{n}=349)\end{array}$ & $88.9 \%$ & $88.1-89.8$ & 8.4 & $<0.01$ \\
\hline $\begin{array}{l}\text { Transmission-based } \\
\text { precautions }(n=338)\end{array}$ & $27.2 \%$ & $25.6-28.8$ & 14.7 & \\
\hline Total $(n=349)$ & $59.8 \%$ & $58.8-60.8$ & 9.3 & \\
\hline
\end{tabular}

Note: $\mathrm{SD}=$ Standard deviation. $\mathrm{IQR}=$ interquartile range. $95 \% \mathrm{Cl}=95 \%$ confidence interval. 


\section{Compliance}

When asked to assess their compliance with a range of IPC activities, the majority of participants indicated that their behaviour was consistent with the best practice, as summarised in Table 2. No association was found between self-reported compliance with IPC activities and gender or age. However, a correlation was identified between the percentage of correctly answered standard precaution questions and the participants' self-reported compliance with three standard precaution activities (Table 3).

\section{Beliefs}

Figure 2 shows the students' beliefs towards a range IPC concepts. Approximately $60 \%$ of the students strongly agreed that a large proportion of HAIs were preventable, MRSA can be transmitted via healthcare workers' hands, aseptic technique should be used in manipulating intravascular devices and that they will receive an annual influenza vaccination. When the respondents were asked whether they will still go to work if they have a cold, $10 \%$ said they will, $25 \%$ were undecided and $65 \%$ said they will not.

The participants held similar views on whether a range of topics posed an infection control problem in Australian hospitals. On a scale of one to four, with one being not a problem and four being a serious problem, the participants rated MRSA $(\times 3.76$, SD 0.46), Clostridium difficile infection $(\times 3.52$, SD 0.65), multi-resistant Gram negative organisms $(\times 3.60, \mathrm{SD} 0.57)$, antibiotic resistance $(\times 3.64$, SD 0.59), low levels of hand hygiene compliance $(\times 3.41$, SD 0.76) and gastroenteritis outbreaks $(\times 3.48$, SD 0.64$)$ as problems. However, the participants viewed low levels of environmental cleanliness $(\times 3.10$, SD 0.88$)$, blood stream infections $(\times 3.13$, SD 0.80$)$, urinary tract infections $(\times 3.22$, SD 0.81$)$ and needle stick injuries $(\times 3.22$, SD 0.80 ) as lesser problems than the previously stated issues. This difference was significant at the 0.05 level. The participants' views on these topics were correlated with the percentage of correctly answered transmissionbased precaution questions. As the percentage of correctly answered transmission-based precaution questions increased, the concern on gastroenterological outbreaks decreased $(\mathrm{r}=-0.128, \mathrm{p}=0.007)$. Conversely, an increased concern on antimicrobial resistance was correlated with an increase in the total percentage of questions correctly answered $(\mathrm{r}=0.093, \mathrm{p}=0.049)$.

\section{Information seeking behaviour}

The participants were most likely to seek IPC information from an infection control professional $(\times 1.82$, SD 0.79 ), followed by organisational policies and guidelines ( $\times 1.89$, SD 0.79 ). They were significantly less likely to seek information from senior nurses, scientific journals and the Internet compared with consulting infection control professionals $(\mathrm{p}<0.001)$ and hospital policies $(\mathrm{p}<$ 0.001 ). As regards information seeking behaviour by age group, those aged less than 25 years were more likely to seek information from senior nurses $(p=0.02)$ and the Internet $(\mathrm{p}=0.02)$ than those aged 25 years and older. Conversely, those aged 25 years and older were more likely to seek information from organisational policies than those aged less than 25 years $(\mathrm{p}=0.02)$.

\section{Discussion}

The nursing students in this study demonstrated inadequate knowledge on IPC, more specifically transmission based precautions, a finding consistent with those of previous studies $[13,21,23]$. The participants demonstrated a considerably stronger level of knowledge on the topic of standard precautions than transmissionbased precautions, with $88.9 \%$ of standard precaution questions correctly answered. The literature indicated mixed results in relation to this theme. Undergraduate healthcare students were found to have an acceptable level of standard precaution knowledge in some studies $[19,25,29]$ and knowledge deficit in others [8]. The low level of knowledge in relation to transmission-based precautions observed in our study is consistent with the findings in the literature [19,30]. We identified only $27.2 \%$ of transmission-based precaution questions

Table 2 Self-reported compliance against infection control procedures $(n=338)$

\begin{tabular}{|c|c|c|c|c|c|}
\hline Statement & Always (n) & Mostly (n) & Occasionally (n) & Rarely (n) & Never (n) \\
\hline I use gloves when I anticipate exposure to blood or bodily fluid & $96 \%(323)$ & $4 \%(14)$ & $0 \%(1)$ & - & - \\
\hline I change gloves between patients & $96 \%(326)$ & $4 \%(10)$ & $0 \%(1)$ & $0 \%(1)$ & - \\
\hline I clean medical equipment after use & $52 \%(177)$ & $37 \%(126)$ & $9 \%(29)$ & $1 \%(4)$ & $1 \%(2)$ \\
\hline I RECAP needles after giving an injection & $3 \%(12)$ & $1 \%(2)$ & $3 \%(10)$ & $11 \%(37)$ & $82 \%(277)$ \\
\hline $\begin{array}{l}\text { I wear eye protection when I am at risk of blood or } \\
\text { body fluid splashes to my eyes }\end{array}$ & $63 \%(214)$ & $26 \%(88)$ & $6 \%(20)$ & $4 \%(14)$ & $1 \%(2)$ \\
\hline I perform hand hygiene before I touch a patient & $82 \%(276)$ & $17 \%(59)$ & $1 \%(3)$ & - & - \\
\hline $\begin{array}{l}\text { I educate, encourage and assist (if needed) my patients to } \\
\text { perform hand hygiene after going to the toilet and before eating. }\end{array}$ & $57 \%(192)$ & $28 \%(95)$ & $10 \%(33)$ & $3 \%(12)$ & $2 \%(6)$ \\
\hline
\end{tabular}


Table 3 Correlations between self-reported compliance infection prevention and control activities and the percentage of correctly answered questions ( $\mathrm{N}=349)$

\begin{tabular}{|c|c|c|c|c|c|c|}
\hline \multirow[b]{2}{*}{ Variables } & \multicolumn{2}{|c|}{$\begin{array}{l}\text { Percentage correctly } \\
\text { answered SBP questions }\end{array}$} & \multicolumn{2}{|c|}{$\begin{array}{l}\text { Percentage correctly } \\
\text { answered TBP questions }\end{array}$} & \multicolumn{2}{|c|}{$\begin{array}{l}\text { Percentage correctly } \\
\text { answered all questions }\end{array}$} \\
\hline & $\begin{array}{l}\text { Correlation } \\
\text { Coefficient }\end{array}$ & $\mathrm{p}$ value & $\begin{array}{l}\text { Correlation } \\
\text { Coefficient }\end{array}$ & $p$ value & $\begin{array}{l}\text { Correlation } \\
\text { Coefficient }\end{array}$ & $p$ value \\
\hline $\begin{array}{l}\text { I use gloves when I anticipate exposure } \\
\text { to blood or bodily fluid }\end{array}$ & 0.113 & 0.02 & 0.006 & 0.90 & 0.068 & 0.15 \\
\hline I change gloves between patients & 0.137 & 0.01 & 0.004 & 0.93 & 0.089 & 0.06 \\
\hline I clean medical equipment after use & 0.016 & 0.74 & -0.090 & 0.05 & -0.062 & 0.17 \\
\hline I recap needles after giving an injection & -0.006 & 0.91 & 0.010 & 0.84 & 0.000 & 0.99 \\
\hline $\begin{array}{l}\text { I wear eye protection when I am at risk } \\
\text { of blood or body fluid splashes to my eyes }\end{array}$ & 0.067 & 0.17 & -0.088 & 0.06 & -0.031 & 0.49 \\
\hline I perform hand hygiene before I touch a patient & 0.101 & 0.04 & -0.087 & 0.07 & -0.012 & 0.80 \\
\hline $\begin{array}{l}\text { I educate, encourage and assist (if needed) my } \\
\text { patients to perform hand hygiene after going } \\
\text { to the toilet and before eating }\end{array}$ & 0.004 & 0.93 & -0.088 & 0.05 & -0.061 & 0.18 \\
\hline
\end{tabular}

Note: $\mathrm{SBP}=$ Standard precautions, $\mathrm{TBP}=$ Transmission-based precautions.

correctly answered. This result suggests that undergraduate education on transmission-based precautions may be inadequate; this observation is particularly pertinent because of the increasing presence of new and evolving pathogens in healthcare environments and the effect of clinician education on reducing the spread of HAIs [11].
We found negative correlations between the participants' increased knowledge of transmission-based precautions and whether they thought specific issues posed an IPC problem in Australian hospitals. Neither gastroenteritis outbreaks, nor hand hygiene compliance were considered to pose a problem. We postulate that a possible reason for this
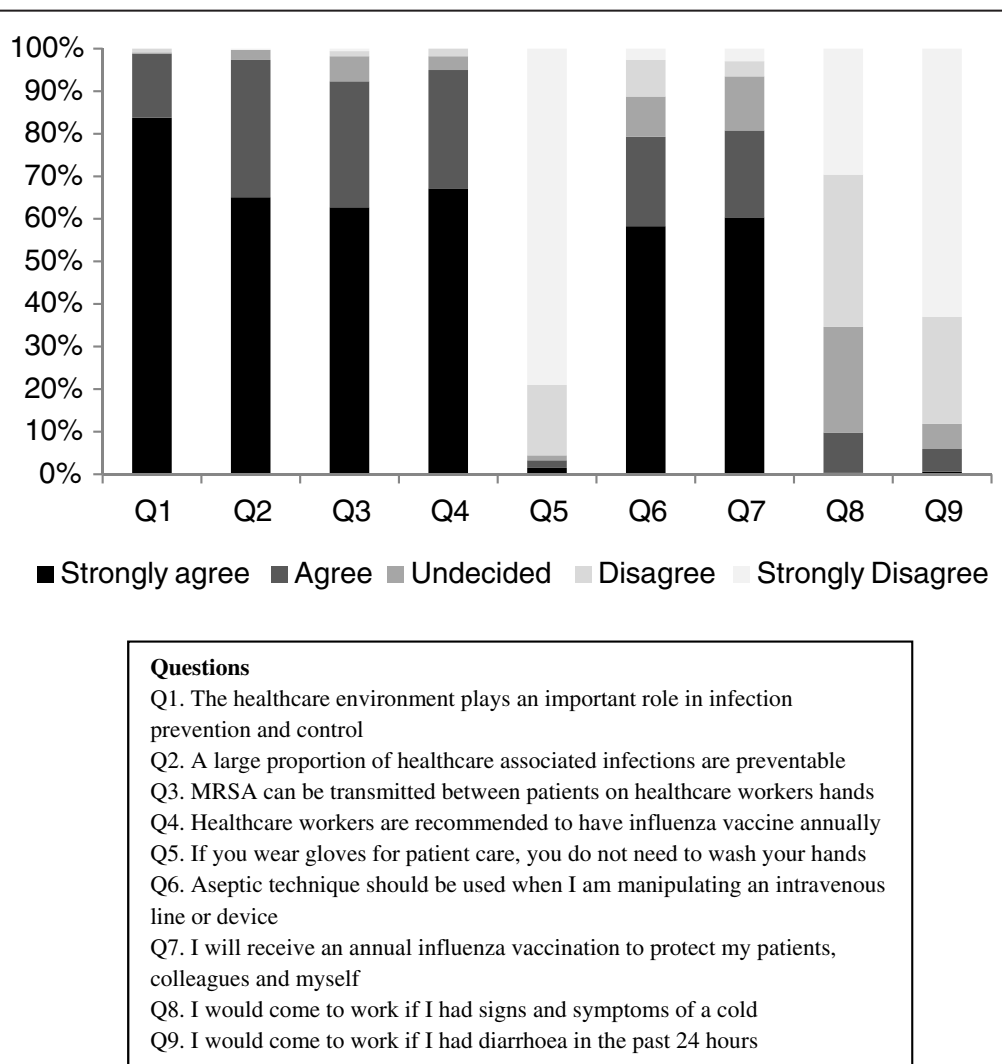

Figure 2 Students' beliefs regarding infection control issues. 
finding is the respondents' experiences and exposure to these issues during their undergraduate education and more specifically, during their clinical placements. For example, graduating nurses may have had little or no nursing experience of a gastroenteritis outbreak. Unless a student nurse has worked in a healthcare setting during an outbreak, he or she may not consider outbreaks as an IPC issue. Furthermore, the participants' view that hand hygiene compliance was less of a problem relative to other scenarios posed can be explained by the popularity of hand hygiene in Australia. The National Hand Hygiene Initiative was introduced across Australia in 2009. This major initiative and its subsequent publicity may have led to the perception that hand hygiene is no longer an issue in healthcare.

Our study also identified some interesting themes on how student nurses obtain IPC information. Several wellreported international studies suggest that nurses prefer to approach colleagues for information rather than access evidence-based resources [31-35]. This pattern of information-seeking behaviour is also evident in graduate and undergraduate nurses, primary health nurses, and acute and critical care nurses [36-38]. As an example, three quarters of the nurses studied by O'leary and Mhaolrunaigh [35] consulted human sources of information on a daily or weekly basis. The literature also reveals that nurses generally ask for information from a colleague perceived to be more knowledgeable or experienced than they are, whereas they considered text-based resources as useful only when these are readily available [35,37]. The fact that the participants in our study were more likely to seek information from an infection control professional is supported by the themes previously discussed and is consistent with the information-seeking behaviour amongst all grades of nurses.

The participants in our study, aged 25 years or younger, were more likely to seek information from senior nurses, compared with those participants who were over 25 years. This finding is consistent with that of an Irish study, which found that compared with more experienced nurses, less experienced ones were reported to more heavily rely on other people for information [35]. Similarly, a UK study found that other staff were likely to influence student nurses' IPC practice [13]. As nurses gain experience, they are more likely to seek information from the next most available information source, for example, policies and guidelines [35]. The reasons cited in the literature for consulting human sources instead of evidence-based information include convenience and efficiency, a perceived lack of computer skills, and avoidance of large amounts of retrieved information which are still to be read, analysed and evaluated [37,38]. O'Leary and Mhaolrunaigh [35] suggest that nurses only search for a limited time to find information which they self-determine to be an acceptable solution and that they do not search long enough to find a solution which they can consider as the 'best decision'. Evidence-based information is therefore recommended to be relevant for practice and must be made readily available [35]. Furthermore, undergraduate nursing curricula should be designed in such a way that they develop the necessary skills for students to understand the importance of and ability to access evidence-based practice.

\section{Limitations}

Our study involves limitations. A cross-sectional web based survey is not an ideal marker of practice. For this reason, our study focused on knowledge, intentions and beliefs rather than self-reported practice. How knowledge is translated into practice by the participants of our study remains unknown. Furthermore, our study surveyed student nurses from different universities which expectedly have different curricula, so the timing of IPC education or skills training also differs. This variation was not properly accounted for in our study. The potential of selection bias also exists in our research. The students were invited via e-mail to participate in the study, and they then decided whether to join. The motivation to participate and whether the motivation was related to academic performance are unknown. Finally, the response rate a response rate of $21 \%$ was achieved for this study, therefore the generalisability of the findings needs to be undertaken with caution.

\section{Conclusion}

We found that in the final phase of their undergraduate education, Australian student nurses had adequate levels of knowledge on standard precautions principles of IPC. However, their knowledge on transmission-based precautions was substandard. Transmission-based precautions are the foundation of IPC for serious organisms and infections, so several implications can be determined. Those responsible for developing undergraduate nursing curricula should consider whether the current approach to IPC used in their respective institutions is effective. For organisations which employ nursing graduates, whether additional IPC training is required should also be seriously considered. Infection prevention and control professionals are often responsible for delivering education in hospitals, and the findings from our study can help them understand the current knowledge gaps in newly qualified nurses to allow for targeted education.

\section{Additional file}

\section{Additional file 1: Survey.}

\section{Competing interests}

This work was supported financially by a competitive grant awarded by Covidien Pty. Ltd. The authors report no conflicts of interest. The authors alone are responsible for the content and writing of the paper. 


\section{Authors' contributions}

BM, AW, FW and RS were involved in the conception and design of the study. BM was responsible for data collection and analysis. All authors were involved in the interpretation of the data, drafting and revising the manuscript and final approval for submission.

\section{Acknowledgements}

The authors wish to acknowledge all the Heads of School from the participating institutions for the support in gaining access to final year nursing students.

\section{Funding}

Funding for this study, which was obtained through a competitive grant process, was awarded by Covidien Pty Ltd.

\section{Author details}

${ }^{1}$ Faculty of Nursing and Health, Avondale College of Higher Education, Wahroonga, NSW 2076, Australia. ${ }^{2}$ School of Nursing, Midwifery and Paramedicine, Australian Catholic University, Dickson, ACT, Australia. ${ }^{3}$ School of Health Sciences, University of Tasmania, Hobart, TAS 7005, Australia. ${ }^{4}$ Department of Health and Human Services, Tasmanian Infection Prevention and Control Unit, Hobart, Tasmania, Australia.

Received: 29 August 2014 Accepted: 24 November 2014

Published online: 12 December 2014

\section{References}

1. National Health and Medical Research Council: Australian Guidelines for the Prevention and Control of Infection in Healthcare (2010). Canberra: National Health and Medical Research Council; 2010.

2. World Health Organisation: Report on the burden of endemic health care-associated infection worldwide. Edited by Allegranzi B. Geneva: World Health Organisation; 2011.

3. Smyth ETM, Mcllvenny G, Enstone JE, Emmerson AM, Humphreys $\mathrm{H}$, Fitzpatrick F, Davies E, Newcombe RG, Spencer RC: Four Country Healthcare Associated Infection Prevalence Survey 2006: overview of the results. J Hosp Infect 2008, 69(3):230-248.

4. Gravel D, Taylor G, Ofner M, Johnston L, Loeb M, Roth V, Stegenga J, Bryce E: The Canadian Nosocomial Infection Surveillance Program, Matlow A. (2007) Point prevalence survey for healthcare-associated infections within Canadian adult acute-care hospitals. J Hosp Infect 2007, 66(3):243-248.

5. Mitchell B, Gardner A, Beckingham W, Fasugba O: Healthcare associated urinary tract infections: a protocol for a national point prevalence study. Healthc Infec 2014, 19(1):26-31.

6. Healthcare Associated Infection (HAl) Prevention Program [http://www. safetyandquality.gov.au/our-work/healthcare-associatedinfection/]

7. Kennedy M, Burnett E: Hand hygiene knowledge and attitudes: comparisons between student nurses. J Infec Prev 2011, 12(6):246-250.

8. Siegel JD, Rhinehart E, Jackson M, Chiarello L: 2007 Guideline for Isolation Precautions: Preventing Transmission of Infectious Agents in Health Care Settings. Am J Infect Control 2007, 35(10 Suppl 2):S65-S164.

9. Zimmerman $\mathrm{P}$, Yeatman $\mathrm{H}$, Jones $\mathrm{M}$ : Frameworks to assist adoption of infection prevention and control programs. Does the literature exist? Healthc Infec 2012, 16(4):129-134.

10. Mitchell BG, Gardner A: Addressing the need for an infection prevention and control framework that incorporates the role of surveillance: a discussion paper. J Adv Nurs 2014, 70(3):533-542.

11. Tropea J, Brand C, Roberts C: A national stakeholder review of Australian infection control programs: the scope of practice of the infection control professional. Sydney: Australian Commission on Safety and Quality in Healthcare; 2008

12. Ward DJ: The role of education in the prevention and control of infection: a review of the literature. Nurse Educ Today 2011, 31(1):9-17.

13. Hinkin J, Cutter J: How do university education and clinical experience influence pre-registration nursing students' infection control practice? A descriptive, cross sectional survey. Nurse Educ Today 2014, 34(2):196-201.

14. Chan R, Molassiotis A, Eunice C, Virene C, Becky H, Chit-ying L, Pauline L, Frances S, Ivy Y: Nurses' knowledge of and compliance with universal precautions in an acute care hospital. Int J Nurs Stud 2002, 39(2):157-163.

15. Easton P, Sarma A, Williams F, Marwick C, Phillips G, Nathwani D: Infection control and management of MRSA: assessing the knowledge of staff in an acute hospital setting. J Hosp Infect 2007, 66(1):29-33.
16. Stein AD, Makarawo TP, Ahmad MFR: A survey of doctors' and nurses' knowledge, attitudes and compliance with infection control guidelines in Birmingham teaching hospitals. J Hosp Infect 2003, 54(1):68-73.

17. Cabana MD, Rand CS, Powe NR, Wu AW, Wilson MH, Abboud PA, Rubin HR: Why don't physicians follow clinical practice guidelines? A framework for improvement. JAMA 1999, 282(15):1458-1465.

18. Chan MF, Ho A, Day MC: Investigating the knowledge, attitudes and practice patterns of operating room staff towards standard and transmission-based precautions: results of a cluster analysis. J Clin Nurs 2008, 17(8):1051-1062.

19. Vandijck D, Labeau S, De Somere J, Claes B, Blot S: Undergraduate nursing students' knowledge and perception of infection prevention and control. J Hosp Infect 2008, 68(1):92-94.

20. Jennings-Sanders A, Jury L: Assessing methicillin-resistant Staphylococcus aureus knowledge among nursing students. Nurse EduC Today 2010, 30(8):789-793.

21. Darawad MW, Al-Hussami M: Jordanian nursing students' knowledge of, attitudes towards, and compliance with infection control precautions. Nurse Educ Today 2013, 33(6):580-583.

22. Askarian M, Honarvar B, Tabatabaee HR, Assadian O: Knowledge, practice and attitude towards standard isolation precautions in Iranian medical students. J Hosp Infec 2004, 58(4):292-296.

23. Al-Hussami M, Darawad M: Compliance of nursing students with infection prevention precautions: effectiveness of a teaching program. Am J Infect Control 2013, 41(4):332-336.

24. Cole M: Exploring the hand hygiene competence of student nurses: a case of flawed self assessment. Nurse Educ Today 2009, 29(4):380-388.

25. Askarian M, Mirzaei K, Mundy L, McLaws M-L: Assessment of knowledge, attitudes, and practices regarding isolation precautions among iranian healthcare workers. Infect Control Hosp Epidemiol 2005, 26(1):105-108.

26. Pessoa-Silva CL, Posfay-Barbe K, Pfister R, Touveneau S, Perneger T, Pittet D: Attitudes and perceptions toward hand hygiene among healthcare workers caring for critically III neonates. Infect Control Hosp Epidemiol 2005, 26(3):305-311.

27. Hand Hygiene Australia Online Learning Package [http://www.hha.org.au/ LearningPackage/olp-home.aspx]

28. International Business Machines Corporation: IBM SPSS Statistics. 200th edition. New York: 2011.

29. Tavolacci MP, Ladner J, Bailly L, Merle V, Pitrou I, Czernichow P: Prevention of nosocomial infection and standard precautions: knowledge and source of information among healthcare students. Infect Control Hosp Epidemiol 2008, 29(7):642-647.

30. Wu CJ, Gardner GE, Chang AM: Taiwanese nursing students' knowledge, application and confidence with standard and additional precautions in infection control. J Clin Nurs 2009, 18(8):1105-1112.

31. Estabrooks CA, O'Leary KA, Ricker KL, Humphrey CK: The Internet and access to evidence: how are nurses positioned? J Adv Nurs 2003, 42(1):73-81.

32. Kosteniuk JG, D'Arcy C, Stewart N, Smith B: Central and peripheral information source use among rural and remote registered nurses. $J \mathrm{Adv}$ Nurs 2006, 55(1):100-114

33. Pravikoff DS, Tanner AB, Pierce ST: Readiness of U.S. nurses for evidencebased practice. Am J Nurs 2005, 105(9):40-51.

34. Thompson C, McCaughan D, Cullum N, Sheldon TA, Mulhall A, Thompson DR: Research information in nurses' clinical decision-making: what is useful? J Adv Nurs 2001, 36(3):376-388.

35. O'Leary DF, Mhaolrunaigh SN: Information-seeking behaviour of nurses: where is information sought and what processes are followed? J Adv Nurs 2012, 68(2):379-390.

36. Marshall AP, West SH, Aitken LM: Preferred information sources for clinical decision making: critical care nurses' perceptions of information accessibility and usefulness. Worldviews Evid Based Nurs 2011, 8(4):224-235.

37. Thompson C, Cullum N, McCaughan D, Sheldon T, Raynor P: Nurses, information use, and clinical decision making-the real world potential for evidence-based decisions in nursing. Evid Based Nurs 2004, 7(3):68-72.

38. Dee C, Stanley EE: Information-seeking behavior of nursing students and clinical nurses: implications for health sciences librarians. J Med Libr Assoc 2005, 93(2):213-222.

doi:10.1186/s12912-014-0043-9

Cite this article as: Mitchell et al:: Australian graduating nurses' knowledge, intentions and beliefs on infection prevention and control: a cross-sectional study. BMC Nursing 2014 13:43. 